\title{
Social introversion and spatial abilities
}

\author{
JOHN GORMLY \\ Rutgers University, New Brunswick, New Jersey \\ and \\ ANNE GORMLY \\ Trenton State College, Trenton, New Jersey
}

\begin{abstract}
A study was conducted to examine the association between the personality trait social introversion, measured by peer ratings, and performance on a test of spatial reasoning, the Block Design subtest of the Wechsler Adult Intelligence Scale. The subjects were 63 men from social fraternities at a state university. Social introversion and performance on the Block Design test correlated $r=.72, p<.001$, indicating a substantial association between these seemingly dissimilar measures of performance. Inasmuch as both variables have high heritability coefficients, it is possible they have a common genetic influence.
\end{abstract}

The viewpoint underlying the research reported here is that molar measures of performance, such as measures of personality variables, can be best understood as outcomes of basic psychological variables such as individual differences in abilities and attention. The purpose of the following study was to extend research on the interdependence of personality characteristics and basic abilities (Haynes \& Gormly, 1977; Hooper, Hooper, \& Colbert, 1984) by investigating the relationship between social introversion, measured by peer ratings, and spatial reasoning, measured by performance on the Block Design subtest of the Wechsler Adult Intelligence Scale. Pilot work by the authors has indicated a substantial relationship between these two variables.

The recognition that individuals differ greatly in their social orientation has been a cornerstone of many theories of personality (Cattell, 1957; Eysenck, 1967; Guilford, 1959; Jung, 1969). There are, however, difficulties in the measurement of sociability; it is difficult to isolate sociability from its correlates. An examination of introversionextroversion reveals that this dimension is influenced by nonsocial personality characteristics. Extroversion includes impulsiveness, excitability, and high rates of physical activity (Eysenck, 1967). Similarly, introversion includes, in addition to low rates of social interaction, seriousness, pessimism, and mistrust of impulses (Eysenck, 1967).

The approach taken in the present research was to use a large group of peer raters who had lived with the research subjects and to ask them to rate social introversion specifically. Asking others to rate a person for social introversion has the potential for confounding two distinct dispositions related to social interactions: (1) a low rate of social interaction resulting from low social interest

Requests for reprints should be sent to: J. Gormly, Department of Psychology, Tillett Hall, Rutgers University, New Brunswick, NJ 08903. (which is the meaning of social introversion as the term is used in this report), and (2) social anxiety, in which case the person is interested in social interactions but avoids them because of apprehension. It would be difficult for observers to distinguish between these two dispositions, which have similar behavioral manifestations. The subjects of the present study were men who had joined social fraternities and who lived in fraternity houses. We assumed that people who voluntarily selected and continued such living arrangements would have minimal levels of social anxiety, and that differences among the subjects in rate of social interactions would be primarily a result of differences in interest.

\section{METHOD}

\section{Subjects}

Two groups of men $(N=32$ and $N=31)$, ranging in age from 19 to 21 , participated in this study. They were members of two social fraternities at a large state university, and they were participating in a continuing project on an experimental approach to personality. They were paid for their participation.

\section{Procedure}

The men were tested individually in the laboratory. Each subject rated the other participating members of his fraternity for social introversion. The rater simply had to decide whether or not each other person could be characterized as socially introverted (having a low rate of social interactions). A person's trait score for social introversion was the proportion of raters who indicated that social introversion was a characteristic of that person. The rating task was embedded in a group of tasks which included the Block Design test.

The Block Design test is a test of spatial reasoning. In this test, there are nine identical cubes: each cube has two red surfaces, two white surfaces, and two red/white surfaces, in which the colors are separated at the diagonal of the surface. The subject is shown a design which can be reproduced by rearrangement of the blocks; he is instructed to reproduce the design as quickly as he can because his performance is being timed. There are 10 designs; the first 6 require only four blocks, and the remaining 4 require all nine blocks. This test was administered using the standard procedure described by Wechsler (1955). 


\section{RESULTS}

The reliability of the raters for judging social introversion was estimated by dividing the raters for each person into two groups and correlating the scores for the two groups; this is the split-half procedure for estimating reliability. The reliabilities of the ratings were very high for both fraternities $(r=.94$ and $r=.89)$. The two groups were then combined into a single sample $(N=63)$.

A rank-order correlation was computed between the social introversion scores and the scores from the Block Design test. The correlation was $r=.72(N=63 ; p<.001)$.

\section{DISCUSSION}

The results of this study indicate that peer ratings of social introversion produce highly reliable scores. That is, there is substantial agreement among peers on who is and who is not socially introverted. The social introversion scores are related to performance on a test of spatial reasoning. The question is, how is it that these seemingly dissimilar variables are so strongly related?

We note that both individual differences in social introversion and individual differences in spatial reasoning have high heritability coefficients. Rose, Harris, Christian, and Nance (1979) reported heritability estimates in excess of $50 \%$ for variance in performance on the Block Design test. Other researchers have consistently reported a high degree of heritability for a variety of measures of sociability (e.g., Loehlin, 1986), including ratings by others (Scarr, 1969). It may be that both social introversion and spatial ability reflect a common genetic influence. Further research is needed to identify what that common influence might be. Our leading hypothesis is that introverted people may have a preference for geometric visual stimuli, which increases their spatial abilities and decreases their rate of social interactions. It is interesting to note that there is a psychiatric syndrome with extreme characteristics that supports this hypothesis. Childhood autism, a syndrome obviously influenced by biological deficiencies, includes low attention toward social stimuli but a well-developed interest in the mechanical aspects of the environment (Weiner \& Elkind, 1972).

\section{REFERENCES}

Cattell, R. B. (1957). Personality and motivation structure and measurement. Yonkers, NY: New World Books.

EYSENCK, H. J. (1967). The biological basis of personality. Springfield, IL: Charles C. Thomas.

GuILford, J. P. (1959). Personality. New York: McGraw-Hill.

HAYNES, J., \& GoRMLY, J. (1977). Anxiety and memory. Bulletin of the Psychonomic Society, 9, 191-192.

HoOPer, F. H., HoOper, J. O., \& ColberT, K. K. (1984). Personality and memory correlates of intellectual functioning: Young adulthood to old age. New York: Karger.

JUNG, C. G. (1969). The collected works of C. G. Jung. Princeton, NJ: Princeton University Press.

LoEHLIN, J. C. (1986). Heredity, environment, and the Thurstone Temperament Schedule. Behavior Genetics, 16, 61-73.

Rose, R. J., Harris, E. L., Christian, J. C., \& NanCe, W. E. (1979). Genetic variance in nonverbal intelligence: Data from the kinship of identical twins. Science, 205, 1153-1154.

SCARR, S. (1969). Social introversion-extroversion as a heritable response. Child Development, 40, 823-832.

WeCHSLER, D. (1955). Manual for the Wechsler Adult Intelligence Scale. New York: Psychological Corporation.

WeINER, I. B., \& ElKIND, D. (1972). Child development: A core approach. New York: Wiley.

(Manuscript received for publication April 25, 1986.) 